\title{
Optimal dose of etanercept in the treatment of rheumatoid arthritis
}

This article was published in the following Dove Press journal:

Open Access Rheumatology: Research and Reviews

24 March 2014

Number of times this article has been viewed

\section{Elizabeth Mary Curtis Jonathan Lewis Marks \\ Department of Rheumatology, University Hospital Southampton, Southampton, Hampshire, UK}

Correspondence: Jonathan Lewis Marks Department of Rheumatology, University Hospital Southampton, Southampton SOI 6 6YD, UK

Tel +442380796452

Fax +442380796965

Emaildr_jonmarks@yahoo.com

\begin{abstract}
Etanercept (ETN) is one of a number of biological therapies targeting the proinflammatory cytokine tumor necrosis factor-alpha that have demonstrated efficacy in the management of rheumatoid arthritis (RA). As experience has grown, a number of different treatment strategies have been investigated to ascertain the optimal conditions for use of ETN in RA and maximize the clinical gains from therapy. These have included the use of higher- and lower-dose treatment regimens, ETN as a monotherapy or in combination with other nonbiologic disease-modifying antirheumatic drugs, the use of ETN in very early clinical disease, and intraarticular ETN administration for resistant synovitis. Recent trials have focused on phased dose reduction or withdrawal of ETN in patients achieving low disease activity states or clinical remission. This review summarizes existing data regarding the optimal timing of ETN initiation and dosing regimens and also evaluates more recent evidence regarding dose-reduction strategies that offer the possibility of biologic-free remission in RA.
\end{abstract}

Keywords: rheumatoid arthritis, etanercept, biologics, antirheumatic agents, monoclonal antibodies, anti-TNF

\section{Introduction}

Rheumatoid arthritis (RA) is a multisystem, chronic, inflammatory disease associated with progressive joint destruction, deformity, and loss of function. Affected individuals experience significant morbidity, disability, ${ }^{1}$ and excess cardiovascular mortality ${ }^{2}$ compared with the general population. To prevent joint damage and consequent disability, a "treat to target" approach aiming for early disease remission through the early use of disease-modifying antirheumatic drugs (DMARDs) and biologic therapies has been proposed. ${ }^{3}$ Because of the chronic nature of RA, medications are often required for many years, making the long-term efficacy, tolerability, and cost of therapeutic agents important factors to consider when making treatment decisions.

Tumor necrosis factor (TNF) has been identified as a key cytokine in the pathogenesis of RA. ${ }^{4}$ Etanercept (ETN; Enbrel ${ }^{\circledR}$; Immunex, Seattle, WA, USA), a genetically engineered protein consisting of two molecules of the extracellular domain of the TNF receptor 2 (p75) and the Fc portion of immunoglobulin G 1, which binds to and inactivates TNF, ${ }^{5,6}$ was approved by the US Food and Drug Administration for the treatment of RA in 1998.

\section{What dose of ETN should be used?}

ETN is currently licensed at a dose of $50 \mathrm{mg} /$ week after a number of dose-ranging trials. Moreland et al compared placebo, ETN $10 \mathrm{mg}$ twice weekly (ETN20), and ETN 
$25 \mathrm{mg}$ twice weekly (ETN50) ${ }^{7}$ in patients with long-standing RA and an inadequate response to DMARDs. Although both treatment arms were significantly better than placebo, ETN50 was significantly more efficacious than ETN20, as measured by American College of Rheumatology ${ }^{8} 20 \%, 50 \%$, and $70 \%$ improvement criteria (ACR 20/50/70), with a greater proportion of patients achieving ACR50 at 6 months (40\% versus [vs] 24\%; $P=0.032$ ). The superior efficacy of ETN50 over ETN20 was confirmed by Bathon et al the following year. ${ }^{9}$

Subsequently, Keystone et al demonstrated equivalent clinical efficacy between $25 \mathrm{mg}$ twice-weekly and $50 \mathrm{mg}$ once-weekly dosing of ETN, thereby improving the convenience of ETN for patients by reducing the frequency of treatment administration. ${ }^{10}$

Two studies have investigated whether higher doses of ETN are more effective than the standard dose. In a 12-week study, patients who were suboptimal responders to methotrexate (MTX) and ETN50 once weekly were randomized to ETN50 twice weekly (ETN100) plus MTX, or ETN50 once weekly plus MTX. At week 12, there was no statistically significant difference in ACR20/50/70 responses between the two treatment groups (ACR50, 13\% vs 8\%). The incidence of serious adverse events including serious infections was higher with ETN100, although this difference was not statistically significant. ${ }^{11}$ In a smaller, 24 -week study of ETN monotherapy after DMARD failure, Johnsen et al compared ETN100 against ETN50. Again, there was no significant difference in clinical efficacy between the two groups (ACR50, $38 \%$ vs $37 \%$ ), but there was a significantly higher incidence of upper respiratory tract infections in the ETN100 treatment group $(26 \%$ vs $4 \% ; P=0.027) .{ }^{12}$

\section{Is ETN monotherapy better than MTX monotherapy?}

Although MTX is effective in slowing the progression of joint destruction and preserving function in early RA, ${ }^{13}$ ETN has a faster onset of action, leading investigators to assess its superiority to MTX as initial therapy for RA. Three studies have compared ETN monotherapy with MTX monotherapy for RA (Table 1).

The Enbrel ERA (early rheumatoid arthritis) trial compared the efficacy of ETN50 monotherapy (25 mg bi-weekly [biw]) with MTX monotherapy in patients with early RA. ${ }^{9}$ During the first 4 months of therapy, ETN achieved significantly greater ACR20/50/70 response rates compared with MTX, but after 6 months, ETN was not significantly better than MTX. At a 2-year follow-up, only the ACR20 was significantly different between ETN and MTX (72\% and 59\%, respectively;
$P=0.005),{ }^{14}$ although ETN demonstrated better outcomes than MTX, as measured by Health Assessment Questionnaire Disability Index (HAQ-DI) score ( $\geq 0.5$ improvement in HAQ, $55 \%$ vs $37 \%$; $P<0.001)$. The proportion of patients with radiographic nonprogression (as measured by $\leq 0.5$ units of change from baseline) in Total Sharp Score (TSS) at 6, 12, and 24 months was also significantly greater for ETN.

Similar findings were reported by the Trial of Etanercept and Methotrexate with Radiographic and Patient Outcomes (TEMPO). ${ }^{15}$ Comparing the ETN50 monotherapy $(25 \mathrm{mg}$ biw) and MTX monotherapy arms, there was no statistically significant difference in the ACR20/50/70 response at the 52-week endpoint (ACR50, 48\% vs 43\%) or at the subsequent 2- and 3-year follow-up. ${ }^{16,17}$

$\mathrm{Hu}$ et $\mathrm{al}^{18}$ demonstrated that $50 \mathrm{mg}$ weekly Yisaipu (Shanghai CP Guojian Pharmaceutical Co. Ltd, Shanghai, People's Republic of China) (a recombinant TNF receptor Fc fusion protein available in the People's Republic of China that has the same structure as ETN) had better efficacy than MTX as measured by ACR 20/50/70 responses at 8 weeks. In line with the other monotherapy studies, this difference was ameliorated after 8 weeks, but the ACR70 response was still significantly greater for ETN from week 16 to study end (ACR70 at week 24, 20\% vs 11\%; $P=0.0185$ ).

\section{Is the combination of ETN plus MTX better than MTX monotherapy?}

The superior efficacy of ETN50 in combination with MTX (ETN50-MTX) versus MTX monotherapy was first demonstrated by Weinblatt et al. ${ }^{19}$ ETN50 (25 mg biw) plus MTX demonstrated significantly better ACR20, ACR50, and ACR70 outcomes at week 24 compared with MTX monotherapy (ACR50, 39\% vs 3\%, respectively; $P<0.001$ ). This finding was confirmed in three subsequent large randomized controlled trials (RCTs) (Table 2). 15,19-20,22

In TEMPO, patients with active RA were randomized to treatment with ETN50 (25 mg biw) plus MTX, MTX monotherapy, or ETN50 (25 mg biw) monotherapy. At week 52, ACR20/50/70 response rates were all significantly better for combination therapy than MTX monotherapy (ACR 50, $69 \%$ vs 43\%; $P<0.0001) .{ }^{15}$ This difference was sustained at the 3 -year point (ACR50 67\% vs 44\%; $P<0.01$ ). The proportion of patients in radiographic remission was also significantly better for combination therapy versus MTX monotherapy at 2 years $(78 \% \text { vs } 60 \% ; P<0.05)^{16}$ and at 3 years $(76 \%$ vs $61 \% ; P<0.05) .{ }^{17}$

Superiority of ETN50-MTX over MTX monotherapy was confirmed by the Combination of Methotrexate and 


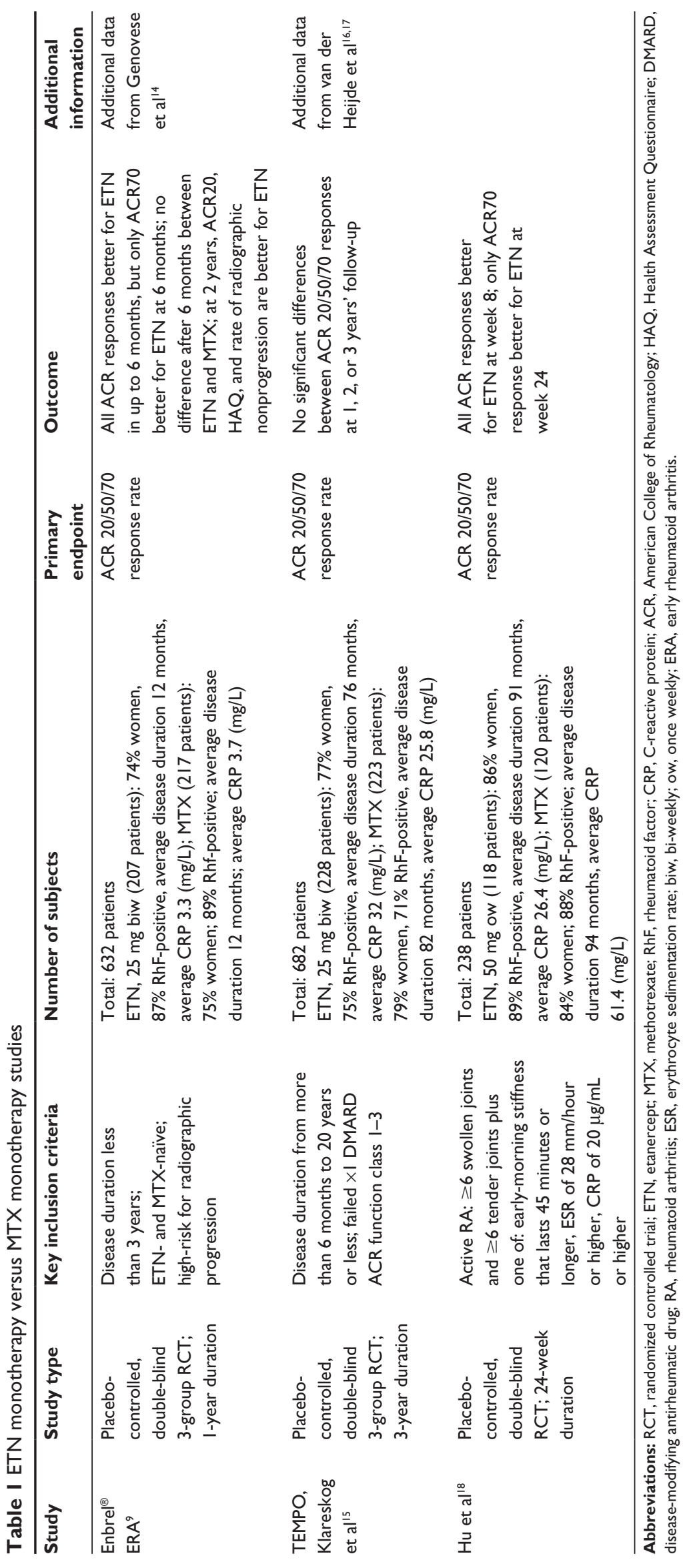




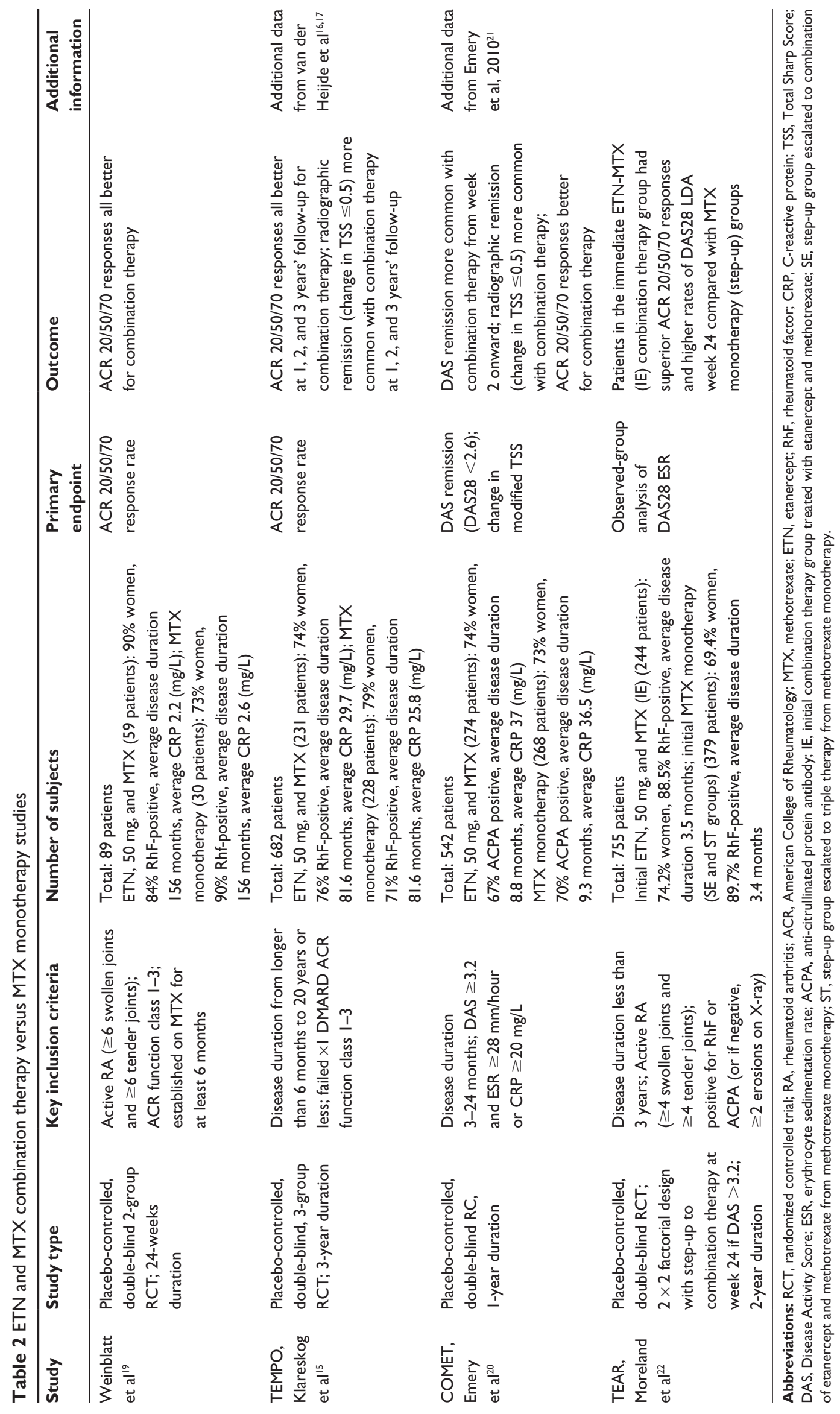


Etanercept in Active Early Rheumatoid Arthritis (COMET) trial, which randomized patients with moderate to severe early RA to receive ETN50 plus MTX (ETN50-MTX) or MTX monotherapy. Disease Activity Score (DAS) remission (DAS28 <2.6) was significantly more likely with combination therapy from week 2 onward and was almost twice as likely at week 52 compared with MTX monotherapy (50\% vs $28 \% ; P<0.0001$ ), with significantly higher ACR responses (ACR50, 71\% vs 49\%; $P<0.0001$ ) and rates of radiographic remission ( $80 \%$ vs $59 \% ; P<0.0001) .{ }^{20}$ In post hoc analysis ${ }^{21}$ the subgroup of patients with very early RA (less than 4 months' disease duration) had even better rates of DAS remission at week 52 for both combination therapy and MTX monotherapy ( $70 \%$ and 35\%, respectively).

More recently, the Treatment of Early Aggressive Rheumatoid Arthritis (TEAR) trial has compared initial treatment with ETN50-MTX to either MTX monotherapy or triple therapy (MTX, sulfasalazine [SSZ], and hydroxychloroquine [HCQ]) in patients with RA of less than 3 years' duration. ${ }^{22}$ Findings at 24 weeks confirmed the superiority of initial combination therapy over MTX monotherapy with better ACR20/50/70 responses (ACR50, $36 \%$ vs $22 \%$, respectively; $P<0.0001)$ and higher rates of DAS28-ESR low disease activity (LDA: $\leq 3.2)(41 \%$ vs $28 \% P<0.0001)$.

\section{Is the combination of ETN plus MTX better than ETN monotherapy?}

The superiority of ETN50-MTX compared with ETN50 monotherapy was first reported by TEMPO, with significantly greater ACR/20/50/70 responses at both 1 year and 3 years (Table 3 ). This finding was subsequently confirmed in a Japanese patient cohort by the Japanese Etanercept Study on Methotrexate Resistance (JESMR). Patients with active RA despite MTX were randomized to receive either ETN50 (25 mg biw) plus MTX or ETN50 (25 mg biw) monotherapy. Combination therapy (adding ETN) resulted in better radiographic and clinical outcomes at both week 24 (ACR50 64\% vs 48\%; $P=0.063)^{23}$ and week 52 (ACR50 77\% vs $44 \% ; P<0.0001)^{24}$ compared with ETN monotherapy.

The only study not to demonstrate additional benefit from ETN50-MTX combination therapy over ETN50 monotherapy for MTX nonresponders is the Add Enbrel Or Replace Methotrexate (ADORE) study. Patients with active RA despite MTX were randomized to either the addition of ETN50 (25 $\mathrm{mg}$ biw) or a switch to ETN50 monotherapy. After 16 weeks, response rates as measured by ACR 20/50/70 were similar between the two groups. ${ }^{25}$

\section{Is the combination of ETN and MTX better than triple therapy?}

The TEAR study (Table 4) took a pragmatic approach to the treatment of early aggressive RA to determine whether initial treatment with ETN50-MTX combination therapy was better than initial triple-therapy (MTX, SSZ, plus HCQ) or MTX monotherapy. At the end of phase I of this study (weeks 1 to 23), there was no significant difference in ACR20/50/70 responses or DAS28-ESR LDA between the initial ETN50MTX and initial triple-therapy arms.

In phase II (from week 24 onwards), participants in the MTX monotherapy arm with a DAS28-ESR of 3.2 or higher were escalated to either ETN50-MTX (addition of ETN) or triple-therapy (addition of SSZ and HCQ). At week 102, there was no significant difference in mean DAS28-ESR between ETN50-MTX and triple-therapy, although the ACR70 response rate at week 102 was significantly better for ETN50-MTX (18\% vs $11 \%$; $P=0.01)$. ETN50-MTX therapy was also associated with a significantly higher rate of radiographic remission compared with triple therapy $\left(77 \%\right.$ vs $66 \% ; P=0.02$ ) at the study end. O'Dell et $\mathrm{al}^{26}$ have also assessed the efficacy of ETN50-MTX combination therapy versus triple therapy (MTX, SSZ, HCQ) in patients with active RA despite treatment with MTX. In the RA: Comparison of Active Therapies (RACAT) trial, triple therapy was shown to be noninferior to ETN50-MTX combination therapy, with equal failure rates ( $27 \%$ for both groups) and DAS28 improvements ( -2.1 vs -2.3 , respectively; $P=0.26$ ) after 48 weeks. ${ }^{26}$

\section{Is ETN effective with DMARDs other than MTX?}

The efficacy of ETN in combination with non-MTX DMARDs, including SSZ, ${ }^{28,29}$ intramuscular gold, HCQ, ${ }^{27}$ and leflunomide (LEF), ${ }^{30,31}$ has been examined in a number of small studies. SSZ has been demonstrated to be safe in combination with ETN. Although combination therapy was not demonstrated to be significantly better than ETN monotherapy during the 24 -week trial by Combe et $\mathrm{al}^{28}$ at 2 years, it was associated with a lower withdrawal rate than SSZ monotherapy, suggesting additional benefit ( $24 \%$ vs $37 \% ; P<0.05) .{ }^{29}$

\section{Can ETN be reduced or withdrawn for patients with low levels of disease activity?}

The advent of biologics therapy has made clinical remission a realistic target for patients with RA. As a consequence, 


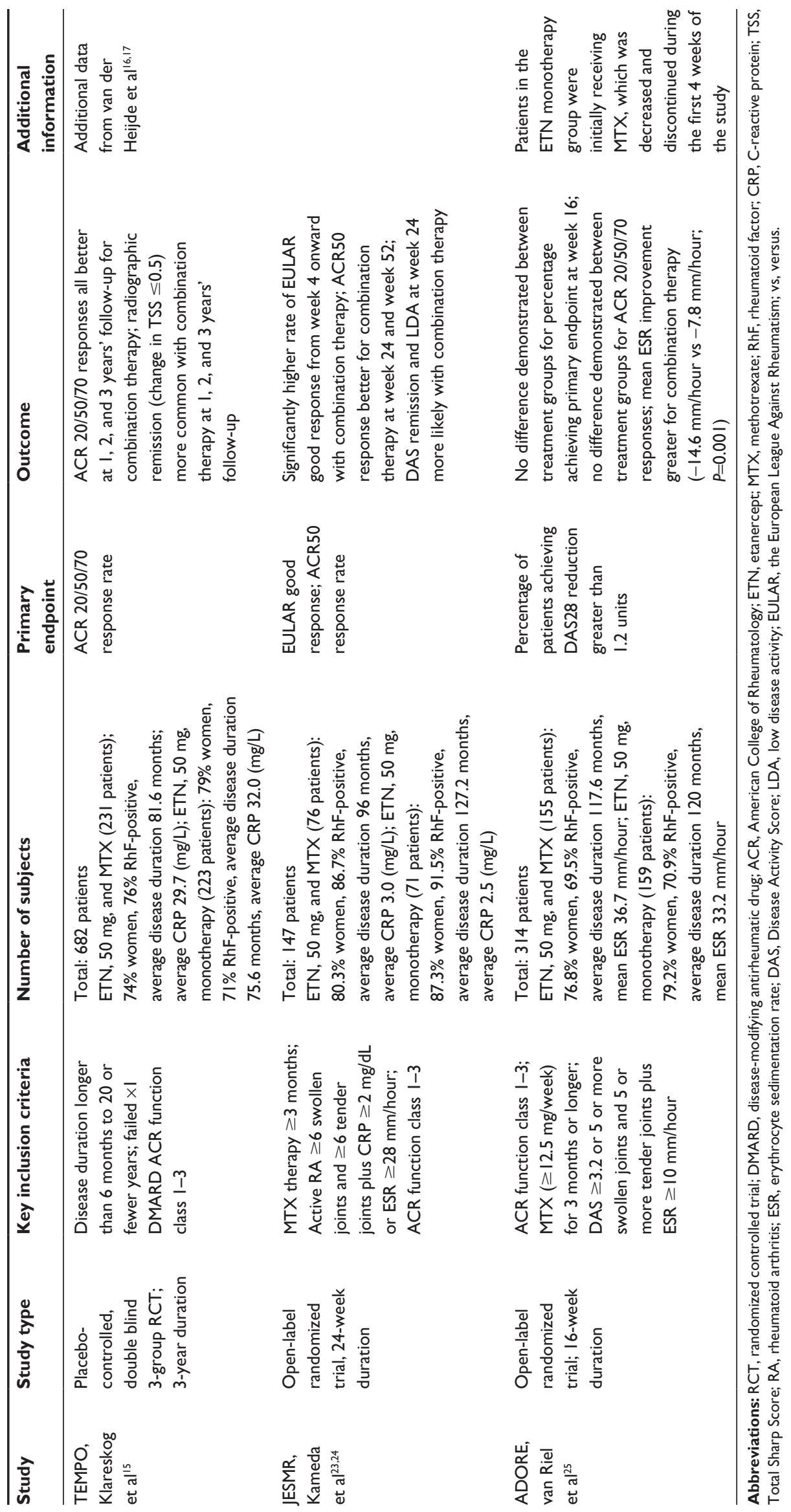



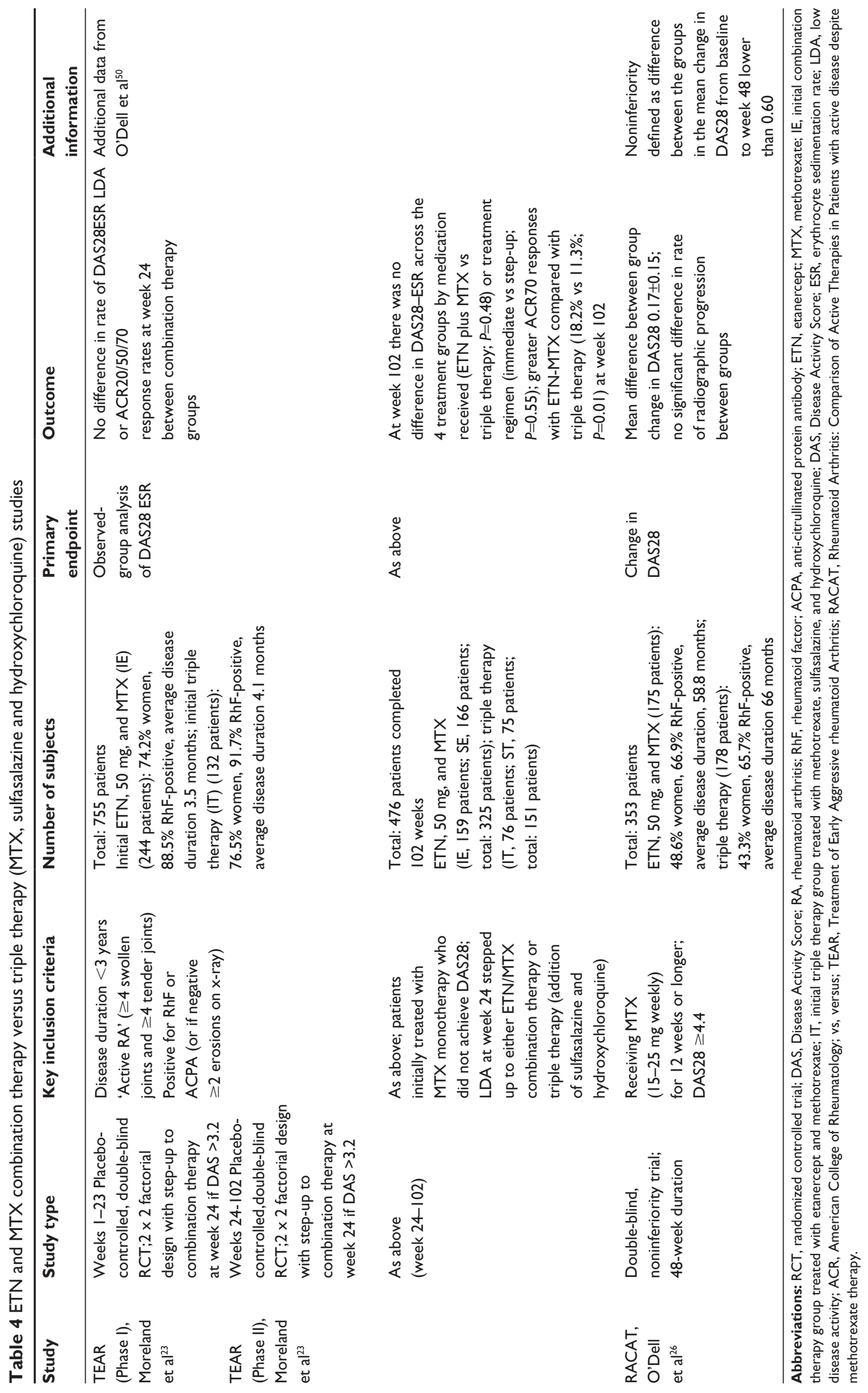
there is growing interest in the possibility of reducing or even withdrawing biologics for those patients in remission, significantly reducing prescribing costs and the risk for medication-related adverse effects. Following observational data to support dose reduction for patients who achieve remission on biologics, ${ }^{32}$ several RCTs (Table 5) are now investigating the feasibility of induction, maintenance, and withdrawal of biologics, including ETN, for patients with RA achieving disease remission or LDA.

In the PRESERVE (Prospective, Randomized Etanercept Study to Evaluate Reduced dose Etanercept combined with MTX versus full dose Etanercept combined with MTX versus MTX alone) trial, Smolen et $\mathrm{al}^{33}$ investigated whether patients with moderately active RA (DAS $>3.2$ and $\leq 5.1$ ) receiving MTX who achieved LDA or DAS remission with ETN50MTX (open-label Phase I of the trial) would maintain a stable disease activity state after ETN withdrawal or ETN dose reduction to $25 \mathrm{mg} /$ week. Patients were randomized to receive ETN50-MTX, ETN25 plus MTX (ETN25-MTX), or placebo plus MTX (PBO-MTX) and followed-up for 52 weeks. The primary endpoint of the study was the proportion of patients who maintained LDA at week 88.

After 88 weeks, the proportion achieving LDA was significantly greater in both the ETN50 and ETN25 treatment arms compared with placebo $(83 \%, 79 \%$, and $43 \%$, respectively; $P<0.0001)$. The proportion achieving DAS remission was significantly greater in the ETN50-MTX and ETN25-MTX arms compared with those in the PBO-MTX group (DAS remission, $66.7 \%, 60.2 \%$, and $29.4 \%$, respectively; $P<0.0001$ for all comparisons). Radiographic nonprogression (change in modified TSS $\leq 2.0)$ was more likely with ETN50 (97\%) compared with placebo $(89 \% ; P=0.0259)$ but was not more likely compared with ETN25 (96\%; $P=0.67)$.

In a similar trial design, van Vollenhoven et al have randomized patients (treated with ETN50 and MTX) who achieved LDA (DAS <3.2) to receive ETN50-MTX, ETN25MTX, or PBO-MTX for the DOSERA (Discontinuing Etanercept in Subjects With Rheumatoid Arthritis) study. ${ }^{34}$ The primary outcome was nonfailure of treatment, which was defined as a DAS28 score higher than 3.2 and either an increase in DAS28 of 0.6 or more or disease progression (as defined by investigator or patient). Early data presented at EULAR 2013 shows that after 48 weeks, the proportion of patients still in LDA (DAS $\leq 3.2$ ) was not significantly different between ETN50-MTX (52\%) and ETN25-MTX (44\%), although both were significantly greater than PBOMTX (13\%). Preliminary data (presented at EULAR 2013) is also available for the Productivity and Remission in a
Randomized Controlled Trial of ETN vs Standard of Care in Early Rheumatoid Arthritis (PRIZE) study. This study is investigating whether treating patients with early RA (less than 6 months duration) who are initially treated with ETN and MTX can maintain remission after ETN dose reduction or withdrawal. ${ }^{35}$ Patients who achieved LDA at 33 weeks and DAS28 remission at 52 weeks (Phase I) were then randomized to receive ETN25 and MTX, MTX monotherapy, or placebo (Phase II). Overall, 66\% achieved DAS28 ESR remission at the end of Phase I, with significantly more patients with moderately active disease (DAS $\geq 3.2-5.1$ ) at randomization likely to achieve this target as those with severe disease (DAS $>5.1 ; 60.3 \%$ vs $44.0 \%$, respectively; $P=0.02) .{ }^{36}$ After 48 weeks, patients receiving ETN25-MTX were significantly more likely to be in DAS28 LDA (88.9\%) than those receiving MTX monotherapy (69.2\%) or placebo-treated patients $(46.2 \%)$. DAS28 remission was more likely in the ETN25MTX group compared with MTX monotherapy or placebo (79.4\%, 53.8\%, and 38.5\%, respectively), as was ACR/ European League Against Rheumatism (EULAR) Boolean remission $\left(67.7 \%, 46.0 \%\right.$, and $22.6 \%$, respectively). ${ }^{37}$

\section{Is ETN effective before clinical RA is present?}

The "window of opportunity" model for RA has led to researchers using DMARDs ${ }^{38}$ and biologic therapies, ${ }^{39}$ including ETN, at the earliest stages of recognizable disease activity. Preliminary data from the Etanercept and Methotrexate to Induce Remission in Patients With Newly Diagnosed Inflammatory Arthritis (EMPIRE) trial ${ }^{40}$ have compared remission rates with ETN50-MTX versus MTX monotherapy as the initial disease-modifying intervention in patients who are either RhF- or Anti-Citrullinated Protein Antibody-positive with synovitis in at least a single joint for less than 3 months. Preliminary data suggest that similar rates of DAS remission are achieved at 1 year (67\% vs $64 \%$; $P=0.688$ ), although patients receiving combination therapy achieve remission earlier.

\section{Is intraarticular ETN an effective treatment strategy for chronic monoarthritis in RA?}

Two double-blind RCTs have investigated the potential of intraarticular (IA) ETN for resistant synovitis in the context of RA. Both studies compared IA ETN (25 mg) with IA corticosteroid, either triamcinolone $16 \mathrm{mg}^{41}$ or methylprednisolone $40 \mathrm{mg},{ }^{42}$ with joint pain improvement as the primary 


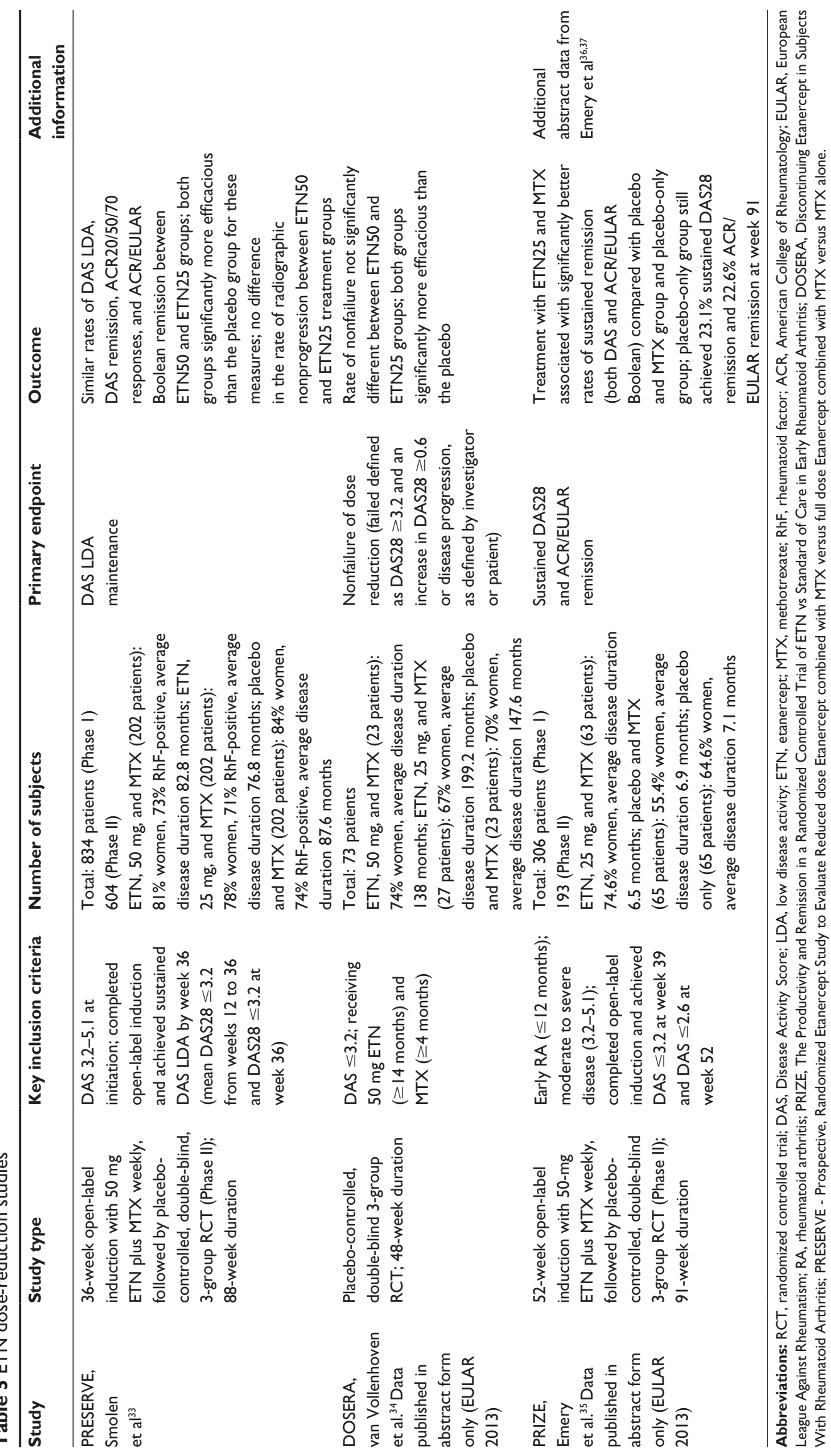


outcome. Although ETN did provide short-term pain relief, neither study demonstrated a significant difference between treatment arms. This finding is in keeping with other RCTs of IA anti-TNF therapy ${ }^{43}$ that have failed to demonstrate superiority over IA corticosteroid for recurrent monoarthritis.

\section{Discussion}

ETN has proven efficacy in RA in both early and late disease. In a recent systematic review and meta-analysis, patients treated with ETN plus DMARD were 34\% more likely to achieve an ACR50 response at 6-36 month points compared with DMARD monotherapy (95\% confidence interval [CI], $26 \%-42 \%$ ) and $20 \%$ more likely than ETN monotherapy (95\% CI, 8\%-32\%). ETN monotherapy was associated with only a 7\% additional likelihood of achieving the ACR50 at 3-36 month points compared with DMARD monotherapy (95\% CI, 1\%-13\%). ${ }^{44}$ It is perhaps surprising that increased doses of ETN have not demonstrated greater efficacy than the licensed $50 \mathrm{mg}$ per week regime. In the context of psoriasis, ETN $100 \mathrm{mg}$ weekly has been shown to be more effective than standard dose, whereas an increased incidence of adverse events was not reported. ${ }^{45-47}$ Some studies have shown that nonresponders to ETN50 have lower serum levels of ETN, ${ }^{48}$ but this finding was not borne out by trial data in which serum levels did not appear to predict response to higher doses of ETN. ${ }^{11}$

Early use of biologics is a highly effective strategy for suppressing inflammation and limiting damage in RA, although superiority over conventional therapy with DMARDs and corticosteroids has not been conclusively proven. ${ }^{49}$ The EMPIRE study is investigating the role of the ETN-MTX combination in early (pre-RA) inflammatory arthritis and has reported high levels of DAS28 remission at 2 years $(67 \%)$, but not levels significantly greater than MTX monotherapy (64\%). ${ }^{40}$ The TEAR study reported that $30 \%$ of patients achieved DAS28 LDA with MTX monotherapy alone and demonstrated that delaying escalation (addition of ETN) for 6 months had no clinical or radiographic adverse outcomes at 2 years. ${ }^{22}$ The rates of remission with MTX monotherapy reported by these studies reinforce the point that not all patients with RA require escalation to biologic therapy. Therefore, where clinically appropriate, a "MTX-first" policy is suitable for patients, even when markers for poor prognosis are present. The noninferiority of triple therapy compared with ETN50-MTX combination therapy is also reassuring, ${ }^{26}$ especially for clinicians operating with restricted access to biologic therapies.
Whether ETN can be used to induce long-term biologicfree remission remains to be determined. The PRESERVE study $^{33}$ has demonstrated that for patients with established RA (average, 83 months) who achieve DAS LDA, withdrawing ETN tends to lead to loss of DAS remission. Preliminary data from the PRIZE study suggests that significantly better clinical outcomes may be achievable if patients with early RA (average, 7 months) are selected for ETN discontinuation. Emery et $\mathrm{al}^{35-37}$ have reported that 1 year after stopped ETN, 46\% of patients receiving MTX monotherapy still achieved ACR/EULAR remission criteria (compared with $11 \%$ for patients receiving MTX monotherapy in PRESERVE), with almost a quarter of patients receiving no active treatment in PRIZE meeting the same goal. For patients reduced to ETN25-MTX, PRIZE demonstrated better DAS28 remission rates than PRESERVE (79\% vs $60 \%$ ), with more than double the proportion achieving ACR/ EULAR remission (68\% vs 33\%). Therefore, disease duration appears to be a significant factor in predicting the future success of a dose-reduction strategy. Using DAS remission (PRIZE) as opposed to DAS LDA (PRESERVE) for the threshold at which to consider patients for dose reduction may be equally important in the higher rates of remission reported at 1 year.

\section{Conclusion}

ETN is a safe and well-tolerated treatment for RA. It has demonstrated efficacy as monotherapy, although combination therapy (usually with MTX) is significantly more clinically effective than either DMARD monotherapy or ETN monotherapy. A MTX-first approach is supported by the current literature, ${ }^{50}$ with escalation to ETN50-MTX combination therapy for those patients not achieving an acceptable level of disease control. Although there are guidelines for biologic initiation in RA, there is currently an absence of published advice for clinicians considering dose reduction of biologic therapies. At this time, the optimum strategy for dose-reducing biologics is uncertain. Ongoing and recently published studies, including PRIZE, ${ }^{51-53}$ should provide important data to aid clinical decision making when considering biologic dose reduction. It appears that for patients achieving LDA or remission, up to $80 \%$ may be maintained in DAS28 remission on reduced dose treatment (ETN25), with up to $40 \%$ able to stop ETN for at least 1 year. Personalized medicine to identify patients likely to require ETN, respond to treatment, and achieve good outcomes with a dose-reduction strategy is set to be a major area of research during the coming years. In some countries, the health economics associated 
with better long-term functional outcomes and reduced prescribing costs are likely to support the lowering of clinical thresholds ${ }^{54}$ at which ETN can be initiated.

\section{Disclosure}

The authors report no conflicts of interest in this work.

\section{References}

1. Pincus T, Callahan LF, Sale WG, Brooks AL, Payne LE, Vaughn WK. Severe functional declines, work disability, and increased mortality in seventy-five rheumatoid arthritis patients studied over nine years. Arthritis Rheum. 1984;27(8):864-872.

2. Aviña-Zubieta JA, Choi HK, Sadatsafavi M, Etminan M, Esdaile JM, Lacaille D. Risk of cardiovascular mortality in patients with rheumatoid arthritis: a meta-analysis of observational studies. Arthritis Rheum. 2008;59(12):1690-1697.

3. Smolen JS, Aletaha D, Bijlsma JW, et al; T2T Expert Committee. Treating rheumatoid arthritis to target: recommendations of an international task force. Ann Rheum Dis. 2010;69(4):631-637.

4. Brennan FM, Chantry D, Jackson A, Maini R, Feldmann M. Inhibitory effect of TNF alpha antibodies on synovial cell interleukin-1 production in rheumatoid arthritis. Lancet. 1989;2(8657):244-247.

5. Moreland LW, Baumgartner SW, Schiff MH, et al. Treatment of rheumatoid arthritis with a recombinant human tumor necrosis factor receptor (p75)-Fc fusion protein. $N$ Engl J Med. 1997;337(3): 141-147.

6. Mohler KM, Torrance DS, Smith CA, et al. Soluble tumor necrosis factor (TNF) receptors are effective therapeutic agents in lethal endotoxemia and function simultaneously as both TNF carriers and TNF antagonists. J Immunol. 1993;151(3):1548-1561.

7. Moreland LW, Schiff MH, Baumgartner SW, et al. Etanercept therapy in rheumatoid arthritis. A randomized, controlled trial. Ann Intern Med. 1999;130(6):478-486.

8. Felson DT, Anderson JJ, Boers M, et al. American College of Rheumatology. Preliminary definition of improvement in rheumatoid arthritis. Arthritis Rheum. 1995;38:727-735.

9. Bathon JM, Martin RW, Fleischmann RM, et al. A comparison of etanercept and methotrexate in patients with early rheumatoid arthritis. N Engl J Med. 2000;343(22):1586-1593.

10. Keystone EC, Schiff MH, Kremer JM, et al. Once-weekly administration of $50 \mathrm{mg}$ etanercept in patients with active rheumatoid arthritis: results of a multicenter, randomized, double-blind, placebo-controlled trial. Arthritis Rheum. 2004;50(2):353-363.

11. Weinblatt ME, Schiff MH, Ruderman EM, et al. Efficacy and safety of etanercept $50 \mathrm{mg}$ twice a week in patients with rheumatoid arthritis who had a suboptimal response to etanercept $50 \mathrm{mg}$ once a week: results of a multicenter, randomized, double-blind, active drug-controlled study. Arthritis Rheum. 2008;58(7):1921-1930.

12. Johnsen AK, Schiff MH, Mease PJ, et al. Comparison of 2 doses of etanercept ( $50 \mathrm{vs} 100 \mathrm{mg}$ ) in active rheumatoid arthritis: a randomized double blind study. J Rheumatol. 2006;33(4):659-664.

13. Rich E, Moreland LW, Alarcón GS. Paucity of radiographic progression in rheumatoid arthritis treated with methotrexate as the first disease modifying antirheumatic drug. J Rheumatol. 1999;26(2): 259-261.

14. Genovese MC, Bathon JM, Martin RW, et al. Etanercept versus methotrexate in patients with early rheumatoid arthritis: two-year radiographic and clinical outcomes. Arthritis Rheum. 2002;46(6):1443-1450.

15. Klareskog L, van der Heijde D, de Jager JP, et al; TEMPO (Trial of Etanercept and Methotrexate with Radiographic Patient Outcomes) study investigators. Therapeutic effect of the combination of etanercept and methotrexate compared with each treatment alone in patients with rheumatoid arthritis: double-blind randomised controlled trial. Lancet. 2004;363(9410):675-681.
16. van der Heijde D, Klareskog L, Rodriguez-Valverde V, et al; TEMPO Study Investigators. Comparison of etanercept and methotrexate, alone and combined, in the treatment of rheumatoid arthritis: two-year clinical and radiographic results from the TEMPO study, a double-blind, randomized trial. Arthritis Rheum. 2006;54(4):1063-1074.

17. van der Heijde D, Klareskog L, Landewé R, et al. Disease remission and sustained halting of radiographic progression with combination etanercept and methotrexate in patients with rheumatoid arthritis. Arthritis Rheum. 2007;56(12):3928-3939.

18. Hu D, Bao C, Chen S, et al. A comparison study of a recombinant tumor necrosis factor receptor:Fc fusion protein (rhTNFR:Fc) and methotrexate in treatment of patients with active rheumatoid arthritis in China. Rheumatol Int. 2009;29(3):297-303.

19. Weinblatt ME, Kremer JM, Bankhurst AD, et al. A trial of etanercept, a recombinant tumor necrosis factor receptor: $\mathrm{Fc}$ fusion protein, in patients with rheumatoid arthritis receiving methotrexate. $N$ Engl $J$ Med. 1999;340(4):253-259.

20. Emery P, Breedveld FC, Hall S, et al. Comparison of methotrexate monotherapy with a combination of methotrexate and etanercept in active, early, moderate to severe rheumatoid arthritis (COMET): a randomised, double-blind, parallel treatment trial. Lancet. 2008;372(9636): 375-382.

21. Emery P, Kvien TK, Combe B, et al. Combination etanercept and methotrexate provides better disease control in very early ( $\leq 4$ months) versus early rheumatoid arthritis ( $>4$ months and $<2$ years): post hoc analyses from the COMET study. Ann Rheum Dis. 2012;71(6): 989-992.

22. Moreland LW, O'Dell JR, Paulus HE, et al; TEAR Investigators. A randomized comparative effectiveness study of oral triple therapy versus etanercept plus methotrexate in early aggressive rheumatoid arthritis: the treatment of Early Aggressive Rheumatoid Arthritis Trial. Arthritis Rheum. 2012;64(9):2824-2835.

23. Kameda H, Ueki Y, Saito K, et al; Japan Biological Agent Study Integrated Consortium. Etanercept (ETN) with methotrexate (MTX) is better than ETN monotherapy in patients with active rheumatoid arthritis despite MTX therapy: a randomized trial. Mod Rheumatol. 2010;20(6):531-538.

24. Kameda H, Kanbe K, Sato E, et al. Continuation of methotrexate resulted in better clinical and radiographic outcomes than discontinuation upon starting etanercept in patients with rheumatoid arthritis: 52-week results from the JESMR study. $J$ Rheumatol. 2011;38(8): $1585-1592$.

25. van Riel PL, Taggart AJ, Sany J, et al; Add Enbrel or Replace Methotrexate Study Investigators. Efficacy and safety of combination etanercept and methotrexate versus etanercept alone in patients with rheumatoid arthritis with an inadequate response to methotrexate: the ADORE study. Ann Rheum Dis. 2006;65(11):1478-1483.

26. O'Dell JR, Mikuls TR, Taylor TH, et al; CSP 551 RACAT Investigators Therapies for active rheumatoid arthritis after methotrexate failure. N Engl J Med. 25, 2013;369(4):307-318.

27. O'Dell JR, Petersen K, Leff R, et al. Etanercept in combination with sulfasalazine, hydroxychloroquine, or gold in the treatment of rheumatoid arthritis. J Rheumatol. 2006;33(2):213-218.

28. Combe B, Codreanu C, Fiocco U, et al; Etanercept European Investigators Network (Etanercept Study 309 Investigators). Etanercept and sulfasalazine, alone and combined, in patients with active rheumatoid arthritis despite receiving sulfasalazine: a double-blind comparison. Ann Rheum Dis. 2006;65(10):1357-1362.

29. Combe B, Codreanu C, Fiocco U, et al; Etanercept European Investigators Network. Efficacy, safety and patient-reported outcomes of combination etanercept and sulfasalazine versus etanercept alone in patients with rheumatoid arthritis: a double-blind randomised 2-year study. Ann Rheum Dis. 2009;68(7):1146-1152.

30. Strangfeld A, Hierse F, Kekow J, et al. Comparative effectiveness of tumour necrosis factor alpha inhibitors in combination with either methotrexate or leflunomide. Annals of the rheumatic diseases. 2009;68(12):1856-1862. 
31. De Stefano R, Frati E, Nargi F, et al. Comparison of combination therapies in the treatment of rheumatoid arthritis: leflunomide-anti-TNFalpha versus methotrexate-anti-TNF-alpha. Clinical Rheumatology. 2010;29(5):517-524.

32. Saleem B, Keen H, Goeb V, et al. Patients with RA in remission on TNF blockers: when and in whom can TNF blocker therapy be stopped? Ann Rheum Dis. 2010;69(9):1636-1642.

33. Smolen JS, Nash P, Durez P, et al. Maintenance, reduction, or withdrawal of etanercept after treatment with etanercept and methotrexate in patients with moderate rheumatoid arthritis (PRESERVE): a randomised controlled trial. Lancet. 2013;381(9870):918-929.

34. van Vollenhoven RV, Franck-Latsson K. In rheumatoid arthritis patients with stable low disease activity on methotrexate plus etanercept, continuation of etanercept at $50 \mathrm{mg}$ or $25 \mathrm{mg}$ weekly are both clinically superior to discontinuation: results from a randomized, 3-arm, double-blind study. Ann Rheumatic Dis. 2013;72 (3):434.

35. Emery P, Szumski A. Radiographic progression in patients with early arthritis treated with etanercept. results from the PRIZE study. Ann Rheumatic Dis. 2013;72(Suppl 3):399.

36. Emery P, Szumski A. Early initiated etanercept plus methotrexate treatment induces remission in patients with either moderate or severe rheumatoid arthritis. Ann Rheumatic Dis. 2013;72(Suppl 3):603.

37. Emery P, Hammoudeh M. Assessing maintenance of remission with reduced dose etanercept plus methotrexate, methotrexate alone, or placebo in patients with early rheumatoid arthritis who achieved remission with etanercept and methotrexate: the PRIZE study. Ann Rheumatic Dis. 2013;72(Suppl 3):399.

38. van Dongen H, van Aken J, Lard LR, et al. Efficacy of methotrexate treatment in patients with probable rheumatoid arthritis: a double-blind, randomized, placebo-controlled trial. Arthritis Rheum. 2007;56(5): 1424-1432.

39. Saleem B, Mackie S, Quinn M, et al. Does the use of tumour necrosis factor antagonist therapy in poor prognosis, undifferentiated arthritis prevent progression to rheumatoid arthritis? Ann Rheum Dis. 2008; 67(8):1178-1180.

40. Villeneuve, Nam E, Hensor JL et al. Preliminary results of a multicentre randomised controlled trial of etanercept and methotrexate to induce remission in patients with newly diagnosed inflammatory arthritis. Arthritis Rheumatism. 2011;63(10):2465.

41. Roux CH, Breuil V, Valerio L, et al. Etanercept compared to intraarticular corticosteroid injection in rheumatoid arthritis: double-blind, randomized pilot study. J Rheumatol. 2011;38(6):1009-1011.

42. Bliddal H, Terslev L, Qvistgaard E, et al. A randomized, controlled study of a single intra-articular injection of etanercept or glucocorticosteroids in patients with rheumatoid arthritis. Scand J Rheumatol. 2006;35(5): $341-345$.
43. van der Bijl AE, Teng YK, van Oosterhout M, Breedveld FC, Allaart CF, Huizinga TW. Efficacy of intraarticular infliximab in patients with chronic or recurrent gonarthritis: a clinical randomized trial. Arthritis Rheum. 2009;61(7):974-978.

44. Lethaby A, Lopez-Olivo MA, Maxwell L, Burls A, Tugwell P, Wells GA. Etanercept for the treatment of rheumatoid arthritis. Cochrane Database Rev. 2013;5:CD004525.

45. Leonardi CL, Powers JL, Matheson RT, et al; Etanercept Psoriasis Study Group. Etanercept as monotherapy in patients with psoriasis. N Engl J Med. 2003;349(21):2014-2022.

46. Gordon KB, Gottlieb AB, Leonardi CL, et al. Clinical response in psoriasis patients discontinued from and then reinitiated on etanercept therapy. J Dermatolog Treat. 2006;17(1):9-17.

47. Papp KA, Tyring S, Lahfa M, et al; Etanercept Psoriasis Study Group. A global phase III randomized controlled trial of etanercept in psoriasis: safety, efficacy, and effect of dose reduction. Br J Dermatol. 2005;152(6):1304-1312.

48. Jamnitski A, Krieckaert CL, Nurmohamed MT, et al. Patients nonresponding to etanercept obtain lower etanercept concentrations compared with responding patients. Ann Rheum Dis. 2012;71(1): 88-91.

49. Nam JL, Villeneuve E, Hensor EM, et al. Remission induction comparing infliximab and high-dose intravenous steroid, followed by treatto-target: a double-blind, randomised, controlled trial in new-onset, treatment-naive, rheumatoid arthritis (the IDEA study). Ann Rheum Dis. 2014;73(1):75-85.

50. O'Dell JR, Curtis JR, Mikuls TR, et al; TEAR Trial Investigators. Validation of the methotrexate-first strategy in patients with early, poorprognosis rheumatoid arthritis: results from a two-year randomized, double-blind trial. Arthritis Rheum. 2013;65(8):1985-1994.

51. Tanaka Y, Takeuchi T, Mimori T, et al; RRR study investigators. Discontinuation of infliximab after attaining low disease activity in patients with rheumatoid arthritis: RRR (remission induction by Remicade in RA) study. Ann Rheum Dis. 2010;69(7):1286-1291.

52. Matsubara T, Ohta S, Mukai M. oRion STUdy GRoUp: Abatacept biologic-free remission study in established rheumatoid arthritis patients. Ann Rheumatic Dis. 2013;72(Suppl 3):613.

53. Kavanaugh A, Emery P, Fleischmann R, van Vollenhoven RF, Pavelka K, Durez $\mathrm{P}$, et al. Withdrawal of adalimumab in early rheumatoid arthritis patients who attained stable low disease activity with adalimumab plus methotrexate: results of a phase 4, double-blind, placebo-controlled trial. [abstract]. Arthritis Rheumatism. 2011;63(Suppl 10):1699.

54. National Institute for Health and Care Excellence. Adalimumab, Etanercept, and Infliximab for the Treatment of Rheumatoid Arthritis. 2007. Available at: http://publications.nice.org.uk/-etanercept-andInfliximab-for-the-treatment-of-rheumatoid-arthritis-ta130. Accessed December 18, 2013.
Open Access Rheumatology Research and Reviews

\section{Publish your work in this journal}

Open Access Rheumatology Research and Reviews is an international, peer-reviewed, open access journal, publishing all aspects of clinical and experimental rheumatology in the clinic and laboratory including the following topics: Pathology, pathophysiology of rheumatological diseases; Investigation, treatment and management of rheumatological

\section{Dovepress}

diseases; Clinical trials and novel pharmacological approaches for the treatment of rheumatological disorders. The manuscript management system is completely online and includes a very quick and fair peerreview system, which is all easy to use. Visit http://www.dovepress.com/ testimonials.php to read real quotes from published authors. 